\title{
11
}

\section{Young Pacific Male Athletes' Experiences of Mental Wellbeing in Elite Rugby Union and Rugby League}

Caleb Marsters and Jemaima Tiatia-Seath

\section{Introduction}

Young Pacific athletes in New Zealand and Australia have been increasingly linked to depression, suicide and other such adverse events, as demonstrated in Australasian media, social networking sites and recent academic studies (Horton 2014; Lakisa et al. 2014; Napier 2015; Panapa \& Phillips 2014; Rodriguez \& McDonald 2013; Tiatia-Seath 2015). While these events and the prominence of Pacific athletes in elite rugby union and rugby league suggest that mental health support should be a priority for this group, gaps remain in the literature relating to the mental wellbeing of young Pacific male athletes, particularly in New Zealand.

Pacific peoples constitute 7.4 per cent of New Zealand's population (Statistics New Zealand 2013), yet Pacific males account for just under 50 per cent of all provincial rugby union players in New Zealand (Field 2013) and 42 per cent of all rugby league players in the National Rugby League (NRL), an elite professional rugby league competition based in Australia and New Zealand (National Rugby League 2016). These percentages are greater in areas with higher Pacific population density, such as Auckland, where Pacific peoples constitute 14 per cent 
of the population but comprise 55 per cent of club rugby players and 67 per cent of the New Zealand Warriors, an Auckland-based professional rugby league team in the NRL (Craig 2018). These figures are expected to rise, as a large proportion of junior representative rugby union and rugby league players have Pacific heritage (Craig 2018; Field 2013).

While this success is an achievement to be cherished and celebrated, there are many transitions and challenges that are associated with participating in elite youth sports and in finding a career in professional sports. Young Pacific athletes are often living away from home for the first time, learning how to deal with freedom and independence, forming new social and professional relationships and are making financial decisions and contractual commitments alongside their familial obligations and on-field pressures to train and perform well (Lakisa et al. 2014; Marsters 2017; Panapa \& Phillips 2014; Zakus \& Horton 2009). These factors can influence the mental health of some young athletes.

Several studies identified that elite athletes may be at an increased risk of experiencing certain mental disorders, such as depression (Doherty et al. 2016; Hughes \& Leavey 2012), anxiety, distress and substance abuse (Gouttebarge et al. 2015a, 2015b; Roberts et al. 2016). Other studies, however, have found that the prevalence of mental illness among elite athletes is comparable to the general population (Gulliver et al. 2015; Markser 2011; Rice et al. 2016; Schaal et al. 2011). Nevertheless, the true rate of mental illness among elite athletes remains unclear, given the paucity of quality research investigating the mental health status of elite athletes.

\section{Setting the Scene}

\section{What Is Mental Wellbeing?}

The World Health Organization (2014) defined mental wellbeing as a state in which an individual can realise their own potential, engage in positive relationships, be resilient in the light of typical life stresses, earn a living and contribute to their community. It is important to note that mental wellbeing is distinct from positive affect, which can come and go, as wellbeing is a stable state of wellness, satisfaction and contentment (Galderisi et al. 2015). Mental wellbeing is often referred to as the foundation of health, but it can also be a goal in itself, with the restoration of mental health a key aspect of mental wellbeing (Keyes 2013). 


\section{Pacific Peoples in New Zealand}

'Pacific peoples' is an umbrella term used to group different ethnic affiliations and peoples that identify as belonging to one or more of the Pacific subregions of Polynesia, Melanesia or Micronesia (Dunsford et al. 2011). In New Zealand, Pacific peoples account for 7.4 per cent of the total population and are expected to comprise 10 per cent of New Zealand's total population by 2026 (Statistics New Zealand 2013). Over half of Pacific peoples, 54.9 per cent, are younger than 25 years old and are mostly New Zealand-born (62.3 per cent), and they are increasingly diverse-with a large number of Pacific young people identifying with multiple ethnic groups (Craig et al. 2008; Statistics New Zealand 2013). People with mixed Pacific and non-Pacific heritage do come under the Pacific peoples umbrella (Tukuitonga 2013). While Pacific peoples are commonly regarded as a homogenous group that is based on its members' similarities, shared experiences, cultural attributes and belief systems, each Pacific ethnic group has their own separate and unique cultural identities, languages, customs, social structures, belief systems, ideologies, histories and worldviews (Finau \& Tukuitonga 2000; Ministry of Health 2008). In this discussion, 'Pacific peoples' refers to people who self-identify as belonging to one or more of the seven largest Pacific population groups in New Zealand: Cook Islands, Fiji, Niue, Samoa, Tokelau, Tonga and Tuvalu (Tukuitonga 2013).

\section{Pacific Male Athletes' Participation in Elite Rugby Union and Rugby League}

Pacific athletes remain central to the cultural and economic growth of both professional rugby codes in New Zealand and Australia, and increasingly in Europe (Zakus \& Horton 2009). Pacific athletes have become key 'commodities' in the global rugby union and rugby league labour markets, and the number of Pacific males playing professionally is expected to increase exponentially worldwide (Zakus \& Horton 2009). The NRL illustrates the growing prominence of Pacific athletes in professional rugby league. In 1996, Pacific athletes comprised only 12 per cent of the NRL's playing rosters, but Pacific athletes today comprise 42 per cent of the players in the NRL and over 50 per cent of players in the NRL's under-20 league-a gross over-representation compared to the relatively small Pacific populations in New Zealand and Australia 
(Field 2013; Ng Shiu \& Vagana 2016; Panapa \& Phillips 2014). Similar trends are prevalent in rugby union (Besnier 2014; Grainger 2008; Zakus \& Horton 2009).

Pacific athletes have become well known for their natural athletic ability, unwavering determination and robust physical traits, which contributes to why Pacific males are highly sought after in both codes of elite rugbyan argument that warrants justified critique, as it fuels the racist stereotype that Pacific athletes are 'all brawn and no brain' (Besnier 2014; Chen 2014; Grainger 2008). The growing visibility of Pacific rugby players in both codes has made a career in professional rugby an attractive prospect for young Pacific males, both financially and as a means to validate their 'masculinity' and attain treasured social and cultural capital for both individual and family alike (Besnier 2014; Horton 2014).

Rugby is deeply entrenched in most Pacific communities, which furthers the tendency for young Pacific males to pursue a career in professional sports (Crocombe 1976; Horton 2014). However, for every Pacific athlete that enjoys a long and prosperous career in professional rugby, there are scores of young Pacific males who do not make it professionally and who, in some instances, experience significant challenges when transitioning away from sports (Besnier 2014; Schofield 2015). Many stressors remain for athletes who can secure professional playing contracts, on top of the fact that a career in both codes of professional rugby is often short, averaging three to four years per player (Price 2007). Alongside greatly publicised expectations and familial responsibilities, this uncertain and high-pressure environment can hamper the mental wellbeing of some athletes (Horton 2014; Teaiwa 2016).

\section{Pacific Mental Wellbeing in New Zealand}

\section{Pacific Perceptions of Mental Wellbeing}

Pacific perceptions of mental health, both traditional and contemporary, differ to those found in mainstream literature. Without making any conclusive generalisations, Western views of mental health are often based on clinical and biomedical paradigms and tend to take an individualised stance (Alefaio 2009; Bush et al. 2009; Pulotu-Endemann et al. 2004; Tiatia 2012; Tukuitonga 2013). Fuimaono Pulotu-Endemann et al. (2004) argued that this is the case because Western perceptions of 
mental health tend to be derived from clinical perspectives that must be objective in their explanations of mental health so that medical diagnoses can be standardised. In most instances, this undermines the subjective nature of mental wellbeing (Pulotu-Endemann et al. 2004). In contrast, Pacific perceptions of mental health are more holistic and are based on collectivism, in which the family forms the foundation for individual and community wellbeing (Pulotu-Endemann et al. 2004).

As most Pacific peoples hold fast to collectivism, it is important to acknowledge the effect of the 'relational self' on Pacific perceptions of mental health (Alefaio 2009; Samu \& Suaalii-Sauni 2009; Tamasese et al. 2005). Bush et al. (2009, p. 142) provided an apt description of the concept of the relational self:

It is a total being comprising spiritual, physical and mental elements which cannot be separated. It derives its sense of wholeness, sacredness and uniqueness, from its place of belonging in family and village, genealogy, language, land environment and culture.

Pacific perceptions of mental wellbeing can be organised into three categories: traditional perceptions, contemporary perceptions and a blend of both (Vaka 2014). Each perspective provides insight into the way that mental health is understood by Pacific peoples and their differing worldviews that are prevalent in Pacific communities (Mila-Schaaf \& Hudson 2009). Factors related to cultural efficacy, religious centrality, mixed ethnicities and Pacific connectedness can lead to differing worldviews, which contributes to this wide spectrum of views of mental wellbeing (Le Va \& Te Pou O Te Whakaaro Nui 2009). While most young Pacific peoples in New Zealand may lean towards contemporary perceptions of mental wellbeing, the holistic and collectivist concept of wellbeing remains for Pacific youth (Bathgate \& Pulotu-Endemann 1997; Puna 2013; Puna \& Tiatia-Seath 2017).

\section{The Mental Wellbeing of Young Pacific Male Athletes in New Zealand}

There is currently a paucity of literature that examines the mental wellbeing of young Pacific male athletes in New Zealand, despite a growing evidence base on the mental wellbeing of Pacific peoples in New Zealand and on Pacific participation in the New Zealand rugby union (Grainger 2008; Schaaf 2006; Te'evale 2001). There is, however, 
an emergent field of research that explores the lived experiences of Pacific male rugby league players in Australia (Horton 2014; Lakisa et al. 2014; Panapa \& Phillips 2014; Rodriguez \& McDonald 2013). While this research provides invaluable insight into the lived experiences of Pacific athletes, there remains a gap in the literature that focuses specifically on the mental wellbeing of young Pacific male athletes. Due to the limitations in the literature regarding this group of athletes, relevant evidence from non-athlete specific Pacific research is used to discuss the mental health context that is related to this group.

Without generalising, the young Pacific male athlete population fall into multiple demographic groups that experience unique disparities in mental health outcomes: Pacific males, Pacific youth and Pacific male youth. Each of these demographic groups experiences higher rates of mental illness and are less likely to access mental health services or to engage in helpseeking behaviours when compared with other New Zealanders (Foliaki et al. 2006; Gulliver et al. 2012; Kessler et al. 2007; Rickwood et al. 2007; Teevale et al. 2016; Vaswani 2011). For example, the onset for more than half of all diagnosed mental illnesses in New Zealand occurs at 18 years or younger, 16-34-year-olds experience the highest rates of mental illness in comparison to other age groups and Pacific males experience the highest rates of admission to acute mental health services in New Zealandthese are all demographics that young Pacific male rugby players fall into (Gulliver et al. 2012; Kessler et al. 2007; Ministry of Health 2008; Oakley Browne et al. 2006; Rickwood et al. 2007).

Pacific youth also face increased challenges to achieving and maintaining mental wellbeing, often exhibiting substantial resilience in the face of adversity (Fa'alili-Fidow et al. 2016; Siataga 2011; Suaalii-Sauni et al. 2009). These disparities are concerning, as 50 per cent of the Pacific population are under the age of 22 and the Pacific youth population in New Zealand is expected to grow exponentially over the next 10 years (Statistics New Zealand 2015). These statistics may or may not be similar for young Pacific male athletes, but they do provide insight into the mental health experiences of young Pacific males in New Zealand.

\section{Suicide and Young Pacific Male Athletes}

Although uncommon, suicide is a concern for young Pacific males in New Zealand. Young New Zealanders aged 15-24 years old experienced the highest rates of suicide among OECD countries in 2016, and the 
attempted suicide rates were three times higher for Pacific youth in comparison to non-Pacific and non-Maori youth in New Zealand (Teevale et al. 2016; Tiatia-Seath et al. 2017). The recent suicide deaths of several young Pacific rugby union and rugby league players in New Zealand, Australia and Europe suggest that these trends may be similar among this group of athletes (Cadzow 2013; Horton 2014; Schofield 2016; TiatiaSeath 2015).

\section{Summary}

In summary, this evidence provides a strong rationale for this research and emphasises the need for further exploration into the mental health of young Pacific male athletes in New Zealand. Reflecting on these concerns, this chapter aims to address two key components of mental health for young Pacific male athletes that seem to have been overlooked in the current literature: how young Pacific male athletes define mental health and what shapes young Pacific male athletes' perceptions of mental health. We will also discuss the implications for researchers, mental health professionals and professionals working with young Pacific male athletes in high-performance environments.

\section{Methodology}

This chapter is derived from a Master's of Public Health, which investigated young Pacific male elite athletes' perceptions and experiences of positive mental wellbeing. A qualitative methodology was utilised to explore young Pacific male athletes' perceptions and experiences of positive mental wellbeing at the elite level (Hammersley 2013; Smith 2015).

\section{Researcher's Positionality}

The lead researcher (Marsters) brought to this research an insideroutsider' perspective (Dwyer \& Buckle 2009). He is an insider because he is a young Pacific male undertaking research in his Pacific community, and an 'outsider' because he has never played sports at the elite level. This means that although he may be from the culture under investigation, he did not have complete knowledge of the subcultures and intersectional identities that exist (Asselin 2003; Dwyer \& Buckle 2009; Puna \& Tiatia-Seath 2017). To address the lead researcher's 'outsider' status, his 
supervisor, who had previously played both codes of rugby at the elite level, supported the integrity of the research. An advisory group consisting of former Pacific elite athletes, current coaches, managers, psychologists and academics with understandings of the professional sports environment and Pacific cultures were also reference points throughout the research. Their knowledge and understanding increased the feeling of confidence in the credibility and rigour of the methodology that was used in this research.

\section{Development of the Semi-Structured Interview Guide}

The interview guide consisted of 11 question zones. The question zones comprised semi-structured, open-ended questions that captured participants' perceptions and experiences of mental wellbeing. The use of a semi-structured interview guide ensured consistency between interviews, without negating the autonomy of participants to openly express their personal thoughts and experiences. Adopting this approach allowed for the collection of rich and in-depth data on participants' views and experiences of mental wellbeing in the context of their own lived experiences. The interview schedule was developed in consultation with experts in the field of Pacific athlete wellbeing and Pacific youth mental wellbeing and from a review of national and international literature.

\section{Recruitment}

Purposeful sampling was used during the recruitment stage. Purposeful sampling is often employed in qualitative research to ensure that the recruitment of information-rich participants is relevant to the phenomena of interest (Liamputtong \& Ezzy 2005; Palinkas et al. 2015). The inclusion criteria for participation was self-identified Pacific heritage, aged 16-24 years, living in Auckland and engaged in an elite rugby league or rugby union program.

To recruit participants, an advertisement was disseminated among the researcher's personal and professional sporting networks to advertise, promote and recruit potential participants. Personal networks included connections via Facebook. The advertisement was also emailed out to elite rugby union and rugby league organisations that had large numbers of young Pacific athletes. These organisations showed interest in the study and shared the advertisement on their websites, among their networks 
and via social networking sites such as Facebook. This approach was very effective, as there were many 'shares', which broadened the advertisement's reach among the target population.

Although this approach was effective, purposive snowball sampling was also used to speed up the recruitment process. It was employed by asking recruited participants to share the research advertisement with other Pacific athletes who met the recruitment inclusion criteria. Typically, participants shared the advertisement with their teammates. Purposeful snowball sampling helped the researcher to build trust and rapport with potential participants. For example, potential participants were more likely to respond to the advertisement if they knew someone who had already participated in the interview process. This approach aligns closely with the Health Research Council of New Zealand's (2014) Pacific Health Research Guidelines, which emphasise the importance of establishing trust and positive relationships when undertaking research with Pacific communities.

A 'participant information sheet' outlining the details of the study was sent electronically to those who responded to the study advertisement. Participation was voluntary and each participant was given the opportunity to ask questions before arranging a convenient time and location for the face-to-face interview. At the face-to-face interviews, the study details were clarified again before the interview was commenced.

\section{Participants}

Twenty young Pacific males participated in this study. The average age of the participants was 19.5 years. The ethnic make-up of participants included those who identified as Tongan $(n=9)$, Samoan $(n=6)$, Samoan/European $(\mathrm{n}=1)$, Samoan/Niuean $(\mathrm{n}=1)$, Cook Islands Māori $(\mathrm{n}=2)$ and Fijian $(\mathrm{n}=1)$. Regarding the sports played, seven participants played rugby league and 13 played rugby union. Four participants were not contracted to any sports club, three were on age-group development contracts, seven were on semi-professional contracts and six were on full, professional contracts. The youngest participant was aged 16 and the oldest was aged 24. A summary of participant demographic information is provided in Table 1 . 
Table 1. Demographic summary of participants

\begin{tabular}{|l|l|l|l|l|l|}
\hline & Age & Ethnicity & Area of residence & Code & Contract \\
\hline 1 & 22 & Tongan & Central Auckland & Union & None \\
\hline 2 & 22 & Samoan & South Auckland & League & Semi-professional \\
\hline 3 & 18 & Samoan & South Auckland & Union & Semi-professional \\
\hline 4 & 19 & Tongan & Central Auckland & Union & Professional \\
\hline 5 & 19 & Tongan & Central Auckland & Union & Professional \\
\hline 6 & 23 & Tongan & West Auckland & League & None \\
\hline 7 & 23 & Fijian & West Auckland & League & None \\
\hline 8 & 19 & Samoan/ & West Auckland & Union & Professional \\
\hline 9 & 19 & Tongan & Central Auckland & Union & Professional \\
\hline 10 & 16 & Cook Islands & South Auckland & Union & None \\
\hline 11 & 21 & Samoan/Niuean & Central Auckland & League & Professional \\
\hline 12 & 16 & Tongan & South Auckland & League & Development \\
\hline 13 & 17 & Samoan & East Auckland & Union & Development \\
\hline 14 & 18 & Tongan & South Auckland & Union & Development \\
\hline 15 & 19 & Samoan & West Auckland & Union & Semi-professional \\
\hline 16 & 18 & Samoan & West Auckland & Union & Semi-professional \\
\hline 17 & 19 & Tongan & South Auckland & Union & Professional \\
\hline 18 & 19 & Tongan & South Auckland & Union & Semi-professional \\
\hline 19 & 24 & Samoan & West Auckland & League & Semi-professional \\
\hline 20 & 19 & Cook Islands & South Auckland & League & Semi-professional \\
\hline & & & & & \\
\hline
\end{tabular}

\section{Data Collection and Analysis}

The one-on-one, face-to-face interviews were conducted in July 2016. Participants selected the time and location for their interview. Locations included local rugby clubrooms, local fast-food establishments, libraries and participants' homes. Interviews lasted between 45 and 90 minutes and were audio recorded, with the participant's permission. All interviews were conducted in English. Interviews were reflective of the Pacific research methodological approach known as talanoa, which provides a safe and culturally appropriate environment for Pacific research participants by using Pacific traditions and protocols during interviews (Vaioleti 2006). 
A grounded theory approach was used to analyse the data collected from interviews. Grounded theory is an inductive method involving the use of constant comparative analysis to analyse data (Glaser 2017; Glaser $\&$ Strauss 1967). Constant comparative analysis utilises three stages of analysis to create emergent categories and to develop theoretical models to explain the data collected and phenomena studied (Corbin \& Strauss 1990). A key function of constant comparative analysis is that data analysis and data collection occur simultaneously, which allows for the two processes to influence one another so that the researcher can focus on, and gain a deeper understanding of, the developing concepts (Glaser $\&$ Strauss 1967). Data analysis was repeated until saturation was reached and no new concepts emerged from the data. This allowed for strong theoretical understandings of the phenomenon to emerge (Corbin \& Strauss 1990). All interviews were transcribed verbatim by the researcher.

\section{Findings and Discussion}

This study entered relatively new ground, with a focus on what mental wellbeing means for young, elite, Pacific male athletes. Participants regarded mental wellbeing holistically, emphasising the importance of family, friends, spirituality, sports and a healthy lifestyle balance. Athletic performance played a central role in participants' definitions of positive mental wellbeing. Last, participants considered personal development, both in and away from sports, important when defining mental wellbeing. Narratives that relate to holistic wellbeing and the balancing of the relational self are presented as findings under five key themes: family support, reciprocating family support, the need for a 'well-balanced' life, athletic performance and personal development.

\section{Family Support}

All participants described the love, support and reassurance of family as essential elements when defining mental wellbeing. Participants agreed that having a positive relationship with family was central to living a positive life and to overcoming any challenges along the way. It was acknowledged that family support helped athletes remain grounded, focused and motivated to self-improve. Participants deemed such 
attributes essential to achieving and maintaining success at the elite level. The following quotes highlight the importance of family support for young Pacific male athletes:

I feel on top of the world aye, but sometimes I get a bit too overboard. So, I remember how I came from humble beginnings. It's not the amount of stuff I have, but the love I get from family and others that makes me feel complete. It helps me keep a positive attitude and remain humble. It's helped me grow. Everyone supporting you makes you feel good; it makes you hungry for more and makes you want to challenge your weaknesses and improve yourself. (P15)

The biggest one for me is family support. Getting that external appreciation from your family, that positive vibe coming from them, a reassuring vibe. It just gives you that happiness inside. (P2)

Consistent with the Pacific mental health literature, a loving and supportive family was the central element of mental wellbeing for this group. This finding illustrates the relational nature of mental wellbeing for these athletes. Additionally, family support intensified athletes' determination to succeed and helped participants remain humble-which were traits that participants perceived as beneficial to supporting mental wellbeing at the elite level. Several other studies have also found family to be a powerful motivator for Pacific rugby union and rugby league players (Horton 2014; Lakisa et al. 2014; Panapa \& Phillips 2014; Schaaf 2006). In the context of mental wellbeing, this may prompt young Pacific male rugby union and rugby league players to place additional pressure on themselves to succeed professionally, which may in turn increase their risk of high anxiety levels (Rice et al. 2016). Not wanting to 'let the family down', for example, may heighten the fear of failure, which would naturally hinder mental wellbeing during stressful or challenging times, which is a well-known phenomenon in the current scholarship relating to Pacific athletes (Horton 2012, 2014; Lakisa et al. 2014; Panapa \& Phillips 2014; Rodriguez \& McDonald 2013). It would be beneficial to investigate the effect of this phenomenon on mental wellbeing in future research. 


\section{Reciprocating Family Support}

Participants noted the importance of reciprocating family support when defining mental wellbeing. Making their families proud and helping their families financially were the two common forms of reciprocity described, as expressed by the following:

It's just being able to provide [financially] for family, and just keeping the family happy. Making them proud. (P4)

I would probably say being able to help, to help family and others. But only when you're at the top of your game, because it's hard to help someone when you're struggling yourself. (P3)

Another central aspect of positive mental wellbeing for these athletes was being able to reciprocate family support, generally by making their families proud and by providing financial stability. This profound desire to reciprocate familial support is prevalent in most studies involving Pacific athletes (Horton 2014; Lakisa et al. 2014; Panapa \& Phillips 2014; Rodriguez \& McDonald 2013). Again, these findings suggest that young Pacific athletes are more likely to internalise pressures to succeed, not just for themselves, but for their families too. Thus, it is vital that family support is visibly exhibited to young athletes when they experience major setbacks in their careers, such as missing out on contracts, not being selected for a representative team, or being unable to provide financial support. However, because young Pacific athletes are more likely to come from lower socioeconomic backgrounds (Statistics New Zealand and Ministry of Pacific Island Affairs 2011), missing out on a lucrative professional sports contract can be a challenging setback for many Pacific athletes and their families.

\section{The Need for A 'Well-Balanced' Life}

Participants defined mental wellbeing as having a well-balanced life. A wellbalanced life was defined by athletes as having the following factors present in their lives: positive relationships with family, positive relationships with friends, a positive relationship with a girlfriend or partner, performing well on the field, successfully balancing any educational or employment responsibilities and having a strong spiritual connection. In short, these factors are present when everything is going 'pretty well'. The following excerpts describe the notion of a well-balanced life for participants: 
It's when you're happy. Mental, emotional, physical, spiritual, and all that. When you're happy in all those areas you could say you are in a positive mental wellbeing ... balanced. An example is when things are good with family, your girlfriend, you're good with God, content, studies are going well, and you're playing well. To me that's positive mental wellbeing. (P11)

I think a combination of everything. When everything off the field is going pretty well, and you're performing well on the field, and you got a good spiritual connection at the same time. Just having all three in a good balance helps. And if one of them was a bit down it would affect other areas because they're all connected in some sort of way. (P13)

Living a well-balanced life was an important aspect of participants' perceptions of mental wellbeing. The positive correlation between 'balance' and mental wellbeing is relatively well-known within the literature on elite rugby union players (Hodge et al. 2008; Horton 2014; Price 2007). In this case, however, participants defined 'balance' in the context of social activities and hobbies involving family and friends-a stark contrast to the literature, which defines 'balance' for athletes as being able to work towards alternative career options away from sports. Essentially, participants prioritised the maintenance of strong familial and social relationships over their perceived need to work towards alternative career options, despite the fact that many participants were actively working towards an alternative career away from sports. Again, this demonstrates the relational nature of these participants and the centrality of positive social relationships for young Pacific athletes. Of practical significance, there may be a potential to support both mental wellbeing and the development of well-balanced athletic identities by incorporating these social relationships into management approaches. When looking to support the mental wellbeing of a Pacific athlete, management must not only think about what is best for the athlete as an individual, but more importantly about what is best for the athlete in the context of their social relations.

\section{Athletic Performance}

Some participants defined mental wellbeing as reaching peak physical fitness and performing well on the field, as illustrated in the following statement: 
[Positive mental wellbeing] is when I'm playing well. And like we have skinfold tests and fitness tests and if my skinfold is going down then I feel real happy and feel like I'm in the best shape to play. (P5)

Participants who prioritised their physical fitness and performance did not entirely neglect other facets of their lives, however:

[Positive mental wellbeing] is when I'm training well and at my peak and best physical wellbeing. But also maintaining a strong connection with family, having time out with the boys, and spiritually as well, being good with God. Just when everything's going good around you and that all goes on to the field and you perform well. (P16)

Overall, participants noted a positive correlation between mental wellbeing and performance on the field:

[Positive mental wellbeing] is just feeling relaxed. I can tell when I'm distracted or worked up about something going into a game. So, my best mindset is being relaxed and enjoying myself and the company around me. Remembering we all started rugby to have fun first. So, enjoying yourself and then performance and everything will come after that. (P17)

Performing well in training and on the field was revealed to be a key constituent of positive mental wellbeing for these athletes. While most athletes agreed that performing well was beneficial to their mental wellbeing, a few participants placed significant emphasis on performing well when it came to defining mental wellbeing, which suggests that these players' mental wellbeing and self-esteem may be heavily invested in external performance appraisal. This is a concern, as previous research has linked high degrees of external performance appraisal and performancebased 'perfectionism' to increased mental illness among athletes (Doherty et al. 2016; Lemyre et al. 2007; Rice et al. 2016).

Placing such an emphasis on performance could indicate that some of these athletes are committing, or have committed, to a foreclosed athletic identity without exploring, or having the opportunity to explore, other avenues away from sports (Doherty et al. 2016; Horton 2014; Price 2007). This is not ideal, as identity foreclosure has been found to intensify the negative psychological effect of poor performances, external criticism, injuries and forced retirement (Clews 2015; Harrison et al. 2011; Hughes 
\& Leavey 2012). There are many studies that explore this phenomenon among non-Pacific athletes, but it would be useful to identify effective strategies to deter the development of foreclosed identities among young Pacific athletes in future research.

\section{Personal Development}

Just under half of the participants acknowledged the importance of personal development when defining mental wellbeing. Participants described personal development as the ability to improve themselves and continually achieve new goals. Athletes defined personal development in the context of rugby as well as off-field activities, such as education, spiritual growth and self-confidence. For example:

I reckon [mental wellbeing] is when you're mentally prepared to do whatever you want ... when you're prepared to take risks to better yourself. So, determined and having the freedom to do want you want ... like some people have boundaries that surround them and they block themselves from doing what they want and reaching their peaks. So that self-confidence to do what you want is positive mental wellbeing to me. (P14)

It appears evident that participants valued their autonomy and the opportunity to improve themselves on and off the field. Formal education was noted by these athletes as an important aspect of personal development. Participants admitted that their parents and team staff constantly reinforced the need to gain a tertiary degree or apprenticeship, which encouraged them to take their education seriously. These findings imply that current strategies to promote 'back-up' career options, and balanced athletic identities, may be working effectively; and, once again, this reveals the benefits of including Pacific players' parents in player welfare initiatives.

In the context of mental wellbeing, this is an important finding, as personal development has been linked with reduced depressive moods and improved self-esteem and self-confidence for young males and young athletes alike (Goodkind et al. 2012; Rice et al. 2016; Woodruff 2016). These findings highlight the potential to support mental wellbeing through personal development initiatives that build on Pacific athletes' determination to improve themselves. It is crucial to acknowledge that personal development does not inherently occur through participation in sports; however, it is imperative that elite sports have programs in place 
that facilitate personal development for young athletes (Newhouse-Bailey et al. 2015). Finding effective ways to develop the life skills required to adjust to life at the elite level was also an area requiring further attention.

\section{Sports and Identity: The Athletic Sense of Self}

Many of the factors important to mental wellbeing for these athletes appear to be rooted in their intersectional identity as Pacific men, young males and elite athletes. Traditional perceptions of what it means to be a Pacific man, for example, are measured by one's ability to contribute financially, to support others and to make their families proud-attributes that are recurrent in participants' perceptions of mental wellbeing (Macpherson $\&$ Macpherson 2009). Other factors contributing to participants' perceptions of mental wellbeing, such as performing well and consistent self-improvement, also align with what it means to be a successful elite athlete. So, there was a strong link between sports and identity for participants in this study.

\section{Strengths, Limitations and Areas for Future Research}

This study is the first qualitative investigation in New Zealand examining young Pacific male athletes' definitions and perceptions of mental wellbeing. The findings cannot yet be generalised to all young Pacific male rugby union and rugby league players, given the sample size, and the views expressed by these participants may not be representative of the wider young Pacific male athlete population in New Zealand. Increasing the sample size and extending the recruitment area would address this and could possibly result in different findings. The voluntary nature of this study may also reduce the representativeness of participants, as self-selection bias may be present. Again, further research with a greater sample size would help address this limitation. While the literature and findings from this research confirm that the Pacific identity is prominent among Pacific athletes in New Zealand, ethnic-specific research should be undertaken in the future to improve the rigour and applicability of research findings in this topic area. 


\section{Conclusion}

Young Pacific male rugby union and rugby league players view positive mental wellbeing as the culmination of several interconnected factors. For these young Pacific male athletes, if one factor suffers then mental wellbeing as a whole suffers, so it is particularly important that athletes are supported during these times and that the 'balance' between these factors is restored. The holistic and relational way that participants viewed mental wellbeing reaffirms the views of Pacific scholarship that states that Pacific peoples view wellbeing in a holistic way, and it highlights the importance of familial servitude and social belonging for these athletes (Alefaio 2009; Bush et al. 2009; Mila-Schaaf \& Hudson 2009; Samu \& Suaalii-Sauni 2009; Tamasese et al. 2005). While participants prioritised lifestyle balance, their perceptions of positive mental wellbeing, away from family and social relationships, were largely centred on sports. This suggests that some of these athletes may be at increased risk of developing overly salient athletic identities (Doherty et al. 2016; Horton 2014; Price 2007). From the findings of this study and existing literature on the topic, the development of balanced athletic identities that prioritise sports, education, strong cultural ties and positive social relationships appears to be crucial to supporting mental wellbeing and resilience among young Pacific male athletes.

\section{Acknowledgements}

Thank you to the Ministry of Health for their financial contribution to this research via the Pacific Health Scholarship. Thank you to the University of Auckland's Faculty of Medical and Health Sciences for their research grant. Ethical approval for this research was granted and obtained from The University of Auckland Human Participants Ethics Committee, Auckland, New Zealand.

\section{References}

Alefaio, S 2009, 'Reflections of a practitioner: Purely a journey of the heart', Pacific Health Dialog, vol. 15, no. 1, pp. 171-176. 
Asselin, ME 2003, 'Insider research: Issues to consider when doing qualitative research in your own setting', Journal for Nurses in Professional Development, vol. 19, no. 2, doi.org/10.1097/00124645-200303000-00008

Bathgate, M \& Pulotu-Endemann, FK 1997, 'Pacific people in New Zealand', in PM Ellis \& SCD Collings (eds), Mental health from a public health perspective, Ministry of Health, Wellington, New Zealand.

Besnier, N 2014, 'Pacific island rugby: Histories, mobilities, comparisons', Asia Pacific Journal of Sport and Social Science, vol. 3, no. 3, pp. 268-276, doi.org/ $10.1080 / 21640599.2014 .982894$

Bush, A, Chapman, F, Drummond, M \& Fagaloa, T 2009, 'Development of a child, adolescent and family mental health service for Pacific young people in Aotearoa/New Zealand', Pacific Health Dialog, vol. 15, no. 1, pp. 138-146.

Cadzow, J 2013, 'Tragic story of rising NRL star Mosese Fotuaika', Sydney Morning Herald, 26 May, viewed 26 May 2016, www.stuff.co.nz/sport/ league/8717606/Tragic-story-of-rising-NRL-star-Mosese-Fotuaika

Chen, CH 2014, 'Prioritizing hyper-masculinity in the Pacific region', Culture, Society and Masculinities, vol. 6, no. 1, p. 69.

Clews, G 2015, Wired to play: The metacognitive athlete, ZebraMAD, Canberra.

Corbin, J \& Strauss, A 1990, 'Grounded theory method: Procedures, canons, and evaluative criteria', Qualitative Sociology, vol. 13, no. 3, pp. 3-21, doi.org/ 10.1007/BF00988593

Craig, E, Taufa, S, Jackson, C \& Han, D 2008, The health of Pacific children and young people in New Zealand, Ministry of Health, Wellington.

Craig, M 2018, 'White flight: A detailed look at race and Auckland rugby', New Zealand Herald, 14 April, viewed 6 September 2018, www.nzherald.co.nz/ sport/news/article.cfm?c_id=4\&objectid=12029746

Crocombe, RG 1976, The Pacific way: An emerging identity, Lotu Pasifika, Suva.

Doherty, S, Hannigan, B \& Campbell, M 2016, 'The experience of depression during the careers of elite male athletes', Frontiers in Psychology, vol. 7, no. 1069, pp. 1-11, doi.org/10.3389/fpsyg.2016.01069

Dunsford, D, Park, J, Littleton, J, Friesen, W, Herda, P, Neuwelt, P, Hand, J, Blackmore, P, Malua, S, Grant, J, Kearns, R, Bryder, L \& Underhill-Sem, Y 2011, Better lives: The struggle for health of transnational Pacific peoples in New Zealand, 1950-2000, 9th edn, University of Auckland, Auckland, viewed 7 March 2018, researchspace.auckland.ac.nz/handle/2292/11030 
Dwyer, S \& Buckle, J 2009, 'The space between: On being an insider-outsider in qualitative research', International Journal of Qualitative Methods, vol. 8, no. 1 , pp. 54-63.

Fa'alili-Fidow, J, Moselen, E, Denny, S, Dixon, R, Teevale, T, Ikihele, A, Adolescent Health Research Group \& Clark, TC 2016, Youth'12 the health and wellbeing of secondary school students in New Zealand: Results for Pacific young people, University of Auckland, Auckland.

Field, M 2013, Polynesian men a global sports commodity, Fairfax Media, viewed 26 May 2016, www.stuff.co.nz/sport/8718872/Polynesian-men-a-globalsports-commodity

Finau, S \& Tukuitonga, C 2000, 'Pacific peoples in New Zealand', in P Davis \& $\mathrm{K}$ Dew (eds), Health and society in Aotearoa/New Zealand, Oxford University Press, Melbourne.

Foliaki, S, Kokaua, J, Schaaf, D \& Tukuitonga, C 2006, 'Pacific people', in MAO Browne, JE Wells \& KM Scott (eds), Te rau hinengaro: The New Zealand mental health survey, Ministry of Health, Wellington, pp. 179-208.

Galderisi, S, Heinz, A, Kastrup, M, Beezhold, J \& Sartorius, N 2015, 'Toward a new definition of mental health', World Psychiatry, vol. 14, no. 2, pp. 231233, doi.org/10.1002/wps.20231

Glaser, B 2017, Discovery of grounded theory: Strategies for qualitative research, Routledge, New York.

Glaser, B \& Strauss, A 1967, The discovery of grounded theory: Strategies for qualitative research, Aldine Publishing Co, Chicago.

Goodkind, J, Lanoue, M, Lee, C, Freeland, L \& Freund, R 2012, 'Feasibility, acceptability, and initial findings from a community-based cultural mental health intervention for American Indian youth and their families', Journal of Community Psychology, vol. 40, no. 4, pp. 381-405, doi.org/10.1002/ jcop. 20517

Gouttebarge, V, Backx, FJG, Aoki, H \& Kerkhoffs, GMMJ 2015a, 'Symptoms of common mental disorders in professional football (soccer) across five European countries', Journal of Sports Science \& Medicine, vol. 14, no. 4, pp. 811-818.

Gouttebarge, V, Frings-Dresen, MHW \& Sluiter, JK 2015b, 'Mental and psychosocial health among current and former professional footballers', Occupational Medicine, vol. 65, no. 3, pp. 190-196, doi.org/10.1093/ occmed/kqu202 
Grainger, AD 2008, 'The browning of the All Blacks: Pacific peoples, rugby, and the cultural politics of identity in New Zealand', PhD thesis, University of Maryland, Maryland, viewed 6 September 2018, drum.lib.umd.edu/ handle/1903/8202

Gulliver, A, Griffiths, K \& Christensen, H 2012, 'Barriers and facilitators to mental health help-seeking for young elite athletes: A qualitative study', BioMed Central Psychiatry, vol. 12, no. 157, pp. 1-14, doi.org/10.1186/1471244X-12-157

Gulliver, A, Griffiths, KM, Mackinnon, A, Batterham, PJ \& Stanimirovic, R 2015, 'The mental health of Australian elite athletes', Journal of Science and Medicine in Sport, vol. 18, no. 3, pp. 255-261, doi.org/10.1016/j.jsams. 2014.04.006

Hammersley, M 2013, 'Defining qualitative research', in M Hammersley (ed.), What is qualitative research?, Bloomsbury Academic, London, pp. 1-20, doi.org/10.5040/9781849666084.ch-001

Harrison, L, Sailes, G, Rotich, WK \& Bimper, AY 2011, 'Living the dream or awakening from the nightmare: Race and athletic identity', Race Ethnicity and Education, vol. 14, no. 1, pp. 91-103, doi.org/10.1080/13613324.201 1.531982

Health Research Council of New Zealand 2014, Pacific health research guidelines 2014, Health Research Council of New Zealand, Auckland.

Hodge, K, Lonsdale, C \& Ng, J 2008, 'Burnout in elite rugby: Relationships with basic psychological needs fulfilment', Journal of Sports Sciences, vol. 26, no. 8, pp. 835-844, doi.org/10.1080/02640410701784525

Horton, P 2012, 'Pacific Islanders in global rugby: The changing currents of sports migration', The International Journal of the History of Sport, vol. 29, no. 17, pp. 2388-2404, doi.org/10.1080/09523367.2012.746834

Horton, P 2014, 'Pacific Islanders in professional rugby football: Bodies, minds and cultural continuities', Asia Pacific Journal of Sport and Social Science, vol. 3, no. 3, pp. 222-235, doi.org/10.1080/21640599.2014.970428

Hughes, L \& Leavey, G 2012, 'Setting the bar: Athletes and vulnerability to mental illness', The British Journal of Psychiatry, vol. 200, no. 2, pp. 95-96, doi.org/10.1192/bjp.bp.111.095976

Kessler, RC, Amminger, GP, Aguilar-Gaxiola, S, Alonso, J, Lee, S \& Ustun, TB 2007, 'Age of onset of mental disorders: A review of recent literature', Current Opinion in Psychiatry, vol. 20, no. 4, pp. 359-364, doi.org/10.1097/ YCO.0b013e32816ebc8c 
Keyes, CLM 2013, 'Promoting and protecting positive mental health: Early and often throughout the lifespan', in CLM Keyes (ed.), Mental well-being: International contributions to the study of positive mental health, Springer Netherlands, Dordrecht, pp. 3-28, doi.org/10.1007/978-94-007-5195-8_1

Lakisa, D, Adair, D \& Taylor, T 2014, 'Pasifika diaspora and the changing face of Australian rugby league', The Contemporary Pacific, vol. 26, no. 2, pp. 347367, doi.org/10.1353/cp.2014.0029

Le Va \& Te Pou O Te Whakaaro Nui 2009, Let's Get Real-Real Skills Plus Seitapu-Working with Pacific Peoples, Le Va, Pasifika within Te Pou, Auckland, New Zealand, viewed 5 September 2017, www.tepou.co.nz/ uploads/files/resource-assets/Lets-Get-Real-Real-Skills-Plus-Seitapu-Workingwith-Pacific-Peoples.pdf

Lemyre, PN, Roberts, GC \& Stray-Gundersen, J 2007, 'Motivation, overtraining, and burnout: Can self-determined motivation predict overtraining and burnout in elite athletes?', European Journal of Sport Science, vol. 7, no. 2, pp. 115-126, doi.org/10.1080/17461390701302607

Liamputtong, P \& Ezzy, D 2005, Qualitative research methods, 2nd edn, Oxford University Press, Melbourne.

Macpherson, C \& Macpherson, L 2009, The warm winds of change: Globalisation and contemporary Samoa, Auckland University Press, Auckland.

Markser, VZ 2011, 'Sport psychiatry and psychotherapy. Mental strains and disorders in professional sports. Challenge and answer to societal changes', European Archives of Psychiatry and Clinical Neuroscience, vol. 261, no. 2, p. 182, doi.org/10.1007/s00406-011-0239-x

Marsters, C 2017, 'Young Pacific male athletes and positive mental wellbeing', Master's thesis, University of Auckland, Auckland.

Mila-Schaaf, K \& Hudson, M 2009, 'The interface between cultural understandings: Negotiating new spaces for Pacific mental health', Pacific Health Dialog, vol. 15, no. 1, pp. 113-119.

Ministry of Health 2008, Pacific peoples and mental health: A paper for the Pacific health and disability action plan review, Ministry of Health, Wellington.

Napier, L 2015, 'Polynesian athletes face stresses and strains in order to give back to families', Sunday Star Times, 19 December, viewed 20 December 2016, www.stuff.co.nz/sport/rugby/75254050/Polynesian-athletes-face-stressesand-strains-in-order-to-give-back-to-families 
National Rugby League 2016, NRL's Pacific strategy grows in Samoa, National Rugby League viewed, viewed 5 September 2017, www.nrl.com/nrls-pacificstrategy-grows-in-samoa/tabid/10874/newsid/101990/default.aspx

Newhouse-Bailey, M, Dixon, M \& Warner, S 2015, 'Sport and family functioning: Strengthening elite sport families', Journal of Amateur Sport, vol. 1, no. 2, pp. 1-26, doi.org/10.17161/jas.v0i0.4934

Ng Shiu, R \& Vagana, N 2016, 'An unlikely alliance: Training NRL “cultural warriors"', In Brief, vol. 2016, no. 10, pp. 1-2.

Oakley Browne, MA, Wells, JE \& Scott, KM (eds) 2006, Te rau hinengaro: The New Zealand mental health survey, Wellington.

Palinkas, LA, Horwitz, SM, Green, CA, Wisdom, JP, Duan, N \& Hoagwood, K 2015, 'Purposeful sampling for qualitative data collection and analysis in mixed method implementation research', Administration and Policy in Mental Health, vol. 42, no. 5, pp. 533-544, doi.org/10.1007/s10488-013-0528-y

Panapa, L \& Phillips, M 2014, 'Ethnic persistence: Towards understanding the lived experiences of Pacific Island athletes in the national rugby league', The International Journal of the History of Sport, vol. 31, no. 11, pp. 13741388, doi.org/10.1080/09523367.2014.924105

Price, N 2007, 'Game of two halves: Preparing young elite rugby players for a future beyond the game', $\mathrm{PhD}$ thesis, University of Wollongong, Wollongong.

Pulotu-Endemann, F, Annandale, M \& Instone, A 2004, A Pacific perspective on the NZ mental health classification and outcomes study, Mental Health Commission, Wellington.

Puna, E 2013, 'New Zealand born Cook Islands youth views towards positive mental wellbeing and suicide prevention', Master's thesis, The University of Auckland, Auckland.

Puna, ET \& Tiatia-Seath, J 2017, 'Defining positive mental wellbeing for New Zealand-born Cook Islands youth', Journal of Indigenous Wellbeing, vol. 2, no. 1, pp. 97-107.

Rice, S, Purcell, R, De Silva, S, Mawren, D, Mcgorry, P \& Parker, A 2016, 'The mental health of elite athletes: A narrative systematic review', Sports Medicine, vol. 1, no. 1, pp. 1-21, doi.org/10.1007/s40279-016-0492-2

Rickwood, DJ, Deane, FP \& Wilson, CJ 2007, 'When and how do young people seek professional help for mental health problems?', Medical Journal of Australia, vol. 187, no. 7, pp. S35-S39. 
Roberts, CM, Faull, AL \& Tod, D 2016, 'Blurred lines: Performance enhancement, common mental disorders and referral in the UK athletic population', Front Psychol, vol. 7, p. 1067, doi.org/10.3389/fpsyg.2016.01067

Rodriguez, L \& McDonald, B 2013, 'After the whistle: Issues impacting on the health and wellbeing of Polynesian players off the field', Asia-Pacific Journal of Health, Sport \& Physical Education, vol. 4, no. 3, pp. 201-215, doi.org/ $10.1080 / 18377122.2013 .836773$

Samu, KS \& Suaalii-Sauni, T 2009, "Exploring the "cultural" in cultural competencies in Pacific mental health', Pacific Health Dialog, vol. 15, no. 1, pp. 120-130.

Schaaf, M 2006, 'Elite Pacific male rugby players' perceptions and experiences of professional rugby', Junctures: The Journal for Thematic Dialogue, vol. 7, pp. 41-54.

Schaal, K, Tafflet, M, Nassif, H, Thibault, V, Pichard, C, Alcotte, M, Guillet, T, El Helou, N, Berthelot, G, Simon, S \& Toussaint, JF 2011, 'Psychological balance in high level athletes: Gender-based differences and sport-specific patterns', PloS One, vol. 6, no. 5, e19007, doi.org/10.1371/journal. pone.0019007

Schofield, D 2015, “Despicable” abuse of young Pacific Island rugby talent a blight on the game', The Telegraph, viewed 10 September 2017, www. stuff.co.nz/sport/71910425/despicable-abuse-of-young-pacific-island-rugbytalent-a-blight-on-the-game

Schofield, D 2016, 'Revealed: How Pacific Island player welfare is being neglected in rugby's "gold rush"', The Daily Telegraph, viewed 10 September 2017, www.telegraph.co.uk/rugby-union/2016/11/16/revealed-how-pacific-islandplayer-welfare-is-being-neglected-in/

Siataga, P 2011, 'Pasifika child and youth well-being: Roots and wings', in Office of the Prime Minister's Science Advisory Committee (ed.), Improving the transition: Reducing social and psychological morbidity during adolescence: A report from the Prime Minister's Chief Science Advisor, Office of the Prime Minister's Science Advisory Committee, Auckland, pp. 153-169.

Smith, JA 2015, Qualitative psychology: A practical guide to research methods, SAGE Publications, London.

Statistics New Zealand 2013, 2013 Census Quickstats about Culture and Identity, Stats NZ, viewed 9 October 2017, www.stats.govt.nz/Census/2013-census/ profile-and-summary-reports/quickstats-culture-identity/pacific-peoples.aspx 
Statistics New Zealand 2015, National Ethnic Population Projections: 2013(Base)2038, Stats NZ, viewed 10 September 2017 (page discontinued), www. stats.govt.nz/ /media/Statistics/Browse\%20for\%20stats/NationalEthnic PopulationProjections/HOTP2013-38/NationalEthnicPopulationProjectio ns2013-38HOTP.pdf

Statistics New Zealand \& Ministry of Pacific Island Affairs 2011, Health and Pacific peoples in New Zealand, Statistics New Zealand and Ministry of Pacific Island Affairs, Wellington.

Suaalii-Sauni, T, Wheeler, A, Saafi, E, Robinson, G, Agnew, F, Warren, H, Erick, M \& Hingano, T 2009, 'Exploration of Pacific perspectives of Pacific models of mental health service delivery in New Zealand', Pacific Health Dialog, vol. 15 , no. 1 , pp. 18-27.

Tamasese, K, Peteru, C, Waldegrave, C \& Bush, A 2005, 'Ole taeao afua, the new morning: A qualitative investigation into Samoan perspectives on mental health and culturally appropriate services', Australian and New Zealand Journal of Psychiatry, vol. 39, pp. 300-309.

Te'evale, T 2001, 'We are what we play: Pacific peoples, sport and identity in Aotearoa', in C Macpherson, P Spoonley \& M Anae (eds), Tangata o te moana nui: The evolving identities of Pacific peoples in Aotearoa/New Zealand, Dunmore Press, Palmerston North, pp. 212-217.

Teaiwa, K 2016, 'Niu mana, sport, media and the Australian diaspora', in M Tomlinson \&T Tengan (eds), New mana: Transformations of a classic concept in Pacific languages and cultures, ANU Press, Canberra, pp. 107-131, doi.org/10.22459/NM.04.2016.04

Teevale, T, Lee, A, Tiatia-Seath, J, Clark, T, Denny, S, Bullen, P, Fleming, T \& Peiris-John, R 2016, 'Risk and protective factors for suicidal behaviors among Pacific youth in New Zealand', The Journal of Crisis Intervention and Suicide Prevention, vol. 37, no. 5, pp. 335-346, doi.org/10.1027/0227-5910/ a000396

Tiatia, J 2012, "Commentary on "cultural diversity across the Pacific": Samoan cultural constructs of emotion, New Zealand-born Samoan youth suicidal behaviours, and culturally competent human services', Journal of Pacific Rim Psychology, vol. 6, no. 2, pp. 75-79, doi.org/10.1017/prp.2012.9

Tiatia-Seath, J 2015, Suicide prevention for Tongan youth in New Zealand, Health Research Council of New Zealand, Auckland.

Tiatia-Seath, J, Lay-Yee, R \& Von Randow, M 2017, 'Suicide mortality among Pacific peoples in New Zealand, 1996-2013', New Zealand Medical Journal, vol. 130 , no. 1454 , pp. $21-29$. 
Tukuitonga, C 2013, 'Pacific people in New Zealand', in IM St George (ed.), Cole's medical practice in New Zealand, 12th edn, Medical Council of New Zealand, Wellington, pp. 66-72.

Vaioleti, TM 2006, 'Talanoa research methodology: A developing position on Pacific research', Waikato Journal of Education, vol. 12, no. 1, pp. 21-34.

Vaka, S 2014, 'A Tongan talanoa about conceptualisations, constructions and understandings of mental illness', PhD thesis, Massey University, Palmerston North, viewed 10 September 2017, mro.massey.ac.nz/handle/10179/5777

Vaswani, N 2011, 'Encouraging help-seeking behaviour among young men: A literature review', Report for the child protection committee, Glasgow City Council, Glasgow, viewed 7 March 2018, pdfs.semanticscholar.org/ 700e/7a88d1c848b183cccc47b63927785e40242f.pdf?_ga=2.203886996. 565400545.1565517978-1387094338.1564090436

Woodruff, RJ 2016, 'An exploratory study of essential life skills for adolescent elite athletes in South Africa', Master's thesis, University of the Western Cape, Cape Town, viewed 10 September 2017, pdfs.semanticscholar.org/ 5c07/339d8335bb5aabab53a0e0d077a6e6544787.pdf

World Health Organization 2014, Mental health: A state of well-being, World Health Organization, viewed 20 December 2016, www.who.int/features/ factfiles/mental_health/en/

Zakus, D \& Horton, P 2009, 'Pasifika in Australian rugby: Emanant cultural, social and economic issues', Sporting Traditions, vol. 26, no. 2, pp. 67-86. 
This text is taken from Pacific Youth: Local and Global Futures, edited by Helen Lee, published 2019 by ANU Press, The Australian National University, Canberra, Australia.

doi.org/10.22459/PY.2019.11 